\title{
Drivers and Directions of Academic Library Development 2005
}

by MICHAEL COTTA-SCHÖNBERG

\begin{abstract}
This paper was presented to the continental section of the European Business Schools Librarians' Group
\end{abstract} (EBSLG), at it's annual meeting in Paris, April 2005.

\section{INTRODUCTION}

The purpose of this paper is not to guess what the future of academic libraries will be, but to identify and understand the present driving forces with a view to choosing and influencing directions of development, which will be advantageous to our users. Four major players will be considered: the ICT-industry, the academic institutions, the publishing industry, and the libraries.

\section{THE ICT-INDUSTRY}

It is evident that developments in technologies of information and communication technologies are a very potent driver of the development of academic libraries. Just think of the importance of clay tablets and papyrus for the development of libraries in the classical age and of Gutenberg's invention of movable types for the development of the modern library. What has surprised many has been the alacrity with which libraries have embraced the new ICT. In many universities the library has been considered to be a pioneer in the application of these technologies. It is evident, however, that the library has no influence whatsoever on the development of these technologies. Therefore, the challenge for libraries is to use these technologies in appropriate ways, and so to speak surf on the ICT-wave - preferably ahead of our users!

\section{THE INTERNET AND THE WEB}

Are the ICT-development and especially the internet as well as the recent personal communication technologies a direct threat to libraries? They may very well be. Those of you, who have seen the movie I robot may remember the desperate accusation of the presumed scoundrel, who cries out - just before he dies: "You would have banned the internet to save the libraries”. And a daily paper in Copenhagen recently featured a headline saying: "The librarian of the future is Google”. So, even if librarians themselves to do not see a possible conflict, others do.

The recent announcement of Google’s project to store millions of pre-copyright books and to make them available on the internet is seen by many as the writing on the wall for libraries. For business libraries as a particular species of libraries this development is not important, though, since business studies to not greatly depend on books from the pre-copyright period. Still, the trend as such is highly significant and for other types of libraries, i.e. great humanities libraries with old collections, it may be very important indeed.

\section{Search engines}

Everybody is now aware that the large search engines, like Google, are extremely good for certain types of information searching of a factual nature, but not very good for other since they simply retrieve too many records at the same time as omitting many relevant records actually retrievable through the net. However, the development of specialized search engines, for example Google Scholar, offers at least two awesome alternatives to traditional library services. Firstly, it seems that they may eventually provide the possibility for integrated catalogue searches among pluralities of libraries combined with localisation facilities directed to particular libraries. Secondly, Google Scholar is already covering a number of publishers of electronic journals, e.g. Blackwell UP, and making the full text available to users from those institutions, for example universities, which subscribe to these periodicals.

I recently searched Google Scholar for literature on supplier relations in connection with product development. One of the first items presented was a highly relevant article from a Blackwell e-journal. I clicked on the item and was immediately transferred to the system of Blackwell UP which recognized me as a user from the Copenhagen Business School (CBS). As the CBS subscribes to Blackwell's e-journals, the system then allowed me to print or download the article directly. So, Google Scholar transferred me to Blackwell UP's web page where the full text article was made directly available to me bypassing completely the library system of the CBS. 
As our users today are directly tuned into the great search engines and only enter the library systems as a second or third choice, this development threatens to render obsolete the library's search facilities for searching its own materials and - as far as e-materials is concerned - also for retrieving them. This challenge is one of the most serious to libraries today. Shall we fight on to be alternatives to the specialised search engines, or should we rather join the flow and systematically make our resources available through search engines?

\section{THE ACADEMIC INSTITUTIONS}

\section{E-learning}

At the Copenhagen Business School the concept of e-learning is a somewhat problematical one. The pedagogical vision of the CBS considers as essential the direct interfacing between teacher and students and between students themselves. Elearning is therefore taken to mean firstly a form of teaching to be included in the ordinary course at the discretion of teachers but not to replace face-to-face teaching. Secondly, it has come to designate e-based support of ordinary and distance teaching, for example in the form of student discussion facilities and the electronic provision of course materials.

Many libraries have developed e-learning facilities in connection with their courses in library instruction which may make them useful partners for their academic institutions in the e-learning development in general. However, there is a much more important task for libraries in the development of dynamic collections of e-based materials for individual university courses. Such collections will become quite essential in the future and replace the traditional printed course packs.

\section{Scholarly publishing}

The present scholarly publishing system has proven very resistant to change. Academic merit still largely depends on publications in high-profile international or US print journals, and there seems to be a perception on the part of university leaders that quality and therefore prestige is bound up with being published in paper in the traditional way. There are important forces counteracting this trend, of course, such as last year's report from a British parliamentary committee on scholarly publishing.

The present system is too costly and cannot cope with the ever-growing demand for academic publishing outlets. Young scholars are happy with e-journals and are aware that peer reviews and all that can perfectly well be maintained in connection with an e-publishing system. Finally, a growing number of important universities are realizing that there may be an alternative to the present system based on universities collaborating in publishing scholarly e-journals and not handing over their research product to publishers. Academic publishing may eventually develop into storing texts on the universities' own servers (open archives) and making them available through branded and quality assured interfaces assuming the format and the functions of the traditional journals.

In the long run, this trend presents a relief for the financial situation of libraries since it will alleviate the cost of periodicals. Universities may of course prefer to confiscate the savings for other purposes, for example for scholarly publishing! Moreover, it offers an opportunity for libraries to provide a new support service for universities in the form of open archives. Some libraries may even become central players in the academic publishing process itself, but it is doubtful that this will be a general trend. Academics will prefer to perform that task themselves.

\section{Dissemination of knowledge to society}

There is a growing trend for societies to expand the mission of universities. Besides the traditional functions of research and teaching the third major task of universities is now seen as dissemination of knowledge to society, including the general public. Academics themselves will of course carry the main responsibility for this work of dissemination, but they will need instruments and service structures to support it. One type is the expert base facilitating the access of the public to individual researchers at the university. Another is the research bulletin couched in popular language. A third is the access interface to the publications of researchers. In this area there is clearly an opportunity for libraries to provide a new service to the university.

\section{Study environments}

Some may have thought, that e-learning and distance learning make the physical university superfluous as a 'place' - in the strict sense of the word - for study. Why should students come to the university in order to study when they can perfectly well do that at home? The general trend seems, however, to be the exact opposite. It appears that intensified ICT-based communication does not diminish the need for young people to be together, directly and physically. A Danish university 
professor has recently proclaimed that the society of the future will not be the digital or the electronic society, but the convivial society.

In the same way, university students come flocking to the physical premises of the universities not only to participate in courses, but also to have study groups, to socialize, and ... to study in libraries. I believe that this trend is permanent: ICT does not abolish the social nature of man, but reinforces it. The trend is therefore an opportunity for libraries in the sense that it underscores the usefulness of one completely traditional library service and ensures an active future for it, independent of the print or electronic format of its collections.

\section{Funding}

Whether there will any general trend concerning the funding of university libraries is difficult to say. However, it may safely be predicted that a great number of libraries will experience a reduction of financial resources over the coming years. One reason will be that the growth of the web-based global information system tends to make the local library less visible and therefore - university managers may think - less necessary. For those libraries financing will be a serious challenge. Keeping the print-based library alive for the next 10-20 years and at the same time developing and expanding the e-library will demand a heavy focus on the optimal use of resources and a radical breakaway from traditional patterns of library expenditure and organization.

\section{THE PUBLISHING INDUSTRY}

\section{E-resources}

The most fundamental driver of academic library development is arguably the strategies of publishers concerning e-journals and e-books. The development of e-journals has definitely not yet run its full course, but it has now developed so far that the end of the print journal as an important information medium for academic libraries is in sight.

The next step is e-books. We shall have to assume that at some point all scholarly and professional literature will be stored electronically, with a number of access options ranging from direct electronic access to print-based access. Exactly where in the future this point may be located is really not important as long as we recognize the trend. What is important is rather to know when the professional and scholarly e-book will cease to be a marginal phenomenon and instead become a major component of our services.

Conventional wisdom in the 1990's was that it would probably take another generation. However, there are signs that major developments may be much closer to us. Among these signs are recent reports from the publishing industry that e-fiction literature now is beginning to take off, which means that publishers will not have to develop special e-production and distribution facilities for scholarly literature, but can simply apply methods developed for the economically much more important fiction area to the scholarly publishing area. This trend is hugely important to libraries. The academic library as we know it, the traditional library, stands and falls with the printed book.

\section{Business model}

As you are aware, the development of e-book services in libraries has until now been hampered by the fact that publishers have not as yet come up with a business model, which makes sense in academic library terms. That will change! A business model for e-books which makes sense to our users - but not necessarily to libraries - might be based on three elements:

\section{Many but cheap transactions}

Quite naturally publishers want to keep and if possible to expand their earnings and profits. As we have seen with eperiodicals they try - and some very successfully - to do this through a pricing strategy based on expensive and therefore relatively few usage transactions. I would recommend the opposite strategy: a pricing strategy based on many and very cheap usage transactions. And when I say cheap, I mean really, really cheap - why not one-cent per download? I am convinced that publishers could earn much more money that way.

\section{Common search facilities}

Publishers would store their e-books on their own servers or on host servers, but instead of trying to force users to search for relevant literature in each publisher's own system they would have to establish a common, user-friendly search facility whether it be a publisher-based system like SCOPUS or a search engine like Google Scholar. 


\section{Direct end user access}

Finally, the business model would comprise and facilitate direct end user access to their system - with no need for passing through local library systems. Whether publishers can truly get their act together and create such a business model, may be doubtful. Their present track record is not promising. But if and when they do establish a radically new business model based on direct user access, libraries will really have to fight to stay in business.

\section{THE LIBRARIES}

What internal forces drive academic library development?

\section{Need to survive}

For one thing, institutions just like people have their need to survive and this applies to libraries, too. Survival is not guaranteed of course, but the very will to survive is necessary for survival, and if libraries loose that drive they have lost their basic dynamism. The fact that libraries want to survive means that they are still alive and kicking and that they may therefore be worth it.

\section{Sense of mission}

But survival instincts are not enough. Happily, libraries today are driven by much more, that is a sense of mission in terms of service and users' needs. Over the last generation there has been a radical transformation of academic libraries. Formerly, focus was to a large extent on books and collections and on cataloguing rules and internal procedures. Today, there is a much clearer sense of a service mission, and this sense not only justifies our continued existence, but it also prepares us for radical transformation, since it is not the library as an institution which is important but the users and their developing needs.

\section{Innovativeness}

The third potent internal driver of academic library development is innovativeness and entrepreneurship, the urge to identify new opportunities, to exploit them and in some cases to create them. Innovativeness is, of course, largely dependent on the individuals working in academic libraries. However, the library's history, culture and structure may seriously hinder or promote innovativeness, and it is therefore very important to promote a culture of innovation and entrepreneurship in our libraries and to develop structures, which facilitate it. Without these three internal drivers of academic library development - need for survival, sense of service mission, and innovativeness - the development of future information services to academics will largely bypass libraries.

\section{DIRECTIONS}

So, there is a number of external and internal drivers of academic library development. What can libraries meaningfully do with them, what directions should they take?

\section{Dehybridization}

A first direction has to do with the hybrid library, in the sense that libraries today must have both print and electronic collections. There is a conscious choice to make whether to pursue the hybrid library as a matter of principle, to continue as long as possible to have print collections, and to remain libraries in the traditional format or - on the other hand - to reduce progressively, systematically and continuously the print element and to aim at the electronic library only. This is a path of dehybridization - not in the sense of returning to the print-based library, but in the sense of leaving it all together.

Academic business libraries will have the possibility of being at the forefront of this development because of one factor: the very high rate of obsolescence of business literature. In business libraries most of the print books lent to students and teachers for that matter have been published within the last 10 years. This means more or less that they shall only need print collections about ten years after the publishers have made all their new books available in e-format. For other types of libraries the development in this area may reasonably be slower, but the direction is the same: towards the e-point. 


\section{Study environments}

To provide an environment conducive to study and concentration is a traditional function of the library and it is still much in demand by students. At the Copenhagen Business School at the same time as the usage of printed books has started to decrease and the usage of electronic resources is developing at an amazing speed, the number of visitors to the library has been increasing annually and attained 1.2 million in 2005. The ordinary academic library of the future may not be a place for printed books, but it will certainly be a place for students and for study. In this sense, the library will continue to have a physical presence in the university providing a fulcrum for the future library organization.

\section{Personal service}

Users will be able to do a lot themselves, and for various reasons - optimization of resources and user satisfaction - libraries shall actively support self-service. However, the global information service available to users - including those information resources subscribed to or owned locally - will be a very complex one, and in spite of the development of specialised search engines, it will become more and more complex.

One of the important challenges for librarians will be to show that they can make a real difference in this respect. The job is to develop the librarian into a highly competent information specialist with a deep knowledge of the functioning of the global information system, with a specialist knowledge of the information resources relevant to the users of the particular institution, and with contact skills and pedagogical skills which translate the specialist competence into a function of advice and guidance useful and attractive to users. Moreover, this service has to be made available to users on the users' own terms, directly in the study environments provided by the library, and indirectly through other means, e.g. electronic means (chat, e-mail, web page, SMS).

\section{The centrifugal library}

The continued existence of the library as a physical place does not mean that the library as an organisation should be physically centred. To the contrary, it may become possible and necessary to have library staff working much closer to the user groups and offering personal services at decentralized service points or possibly through staff working directly with researchers in the institutes. For this to become reality, librarians will have to develop new professional identities and become institute persons rather than library persons, or they will have hybrid identities as library persons and institute persons.

\section{Scholarly publishing and dissemination of knowledge}

Following the lead of our American colleagues, European librarians may add a new function to their traditional ones by engaging in scholarly publishing through the maintenance of open archives and institutional repositories and there may be scope for supporting the publication of marginal journals.

Also, libraries may have an important role to play in the new functions of universities with respect to dissemination of knowledge to the public by developing and maintaining appropriate interfaces to their open archives, through current information on new publications from the university and its researchers, and through expert bases facilitating public access to researchers at universities and business schools.

It is clear, that libraries will in this area have to work together with the communication office of their university, whose function they are not qualified to perform and therefore should not try to take over. The specific role of the library will be to develop the instruments of dissemination and other activities based directly on their repository function for the university's and researchers’ publications.

\section{Information literacy}

The young people do not arrive at the university without information literacy and skills. To the contrary, they have been using personal communication technologies, computers and the web since early childhood. Still, they lack - sometimes to an astonishing degree - information skills at an academic level. The ease of using search engines make them unaware how much relevant information they may be missing, and there is a tendency to use web-based information uncritically. There is, therefore, still scope for the library promoting information literacy at the academic level, either as separate courses or tutorials for students, or as an integrated part of the curriculum, for example in connection with the writing of student papers. 


\section{Search engines: if you cannot beat them, join them}

Search engines are here to stay. Formerly, it was a widespread doctrine that libraries should teach users to use the library's own catalogue as the first step in information searching and only proceed to engine searching as their second choice. This position is being or has already been abandoned - at least by library users! It may be foreseen that in the future searching any library's information resources will happen through specialised search engines, for example Scholar Google and not through local library catalogues.

We are definitely not there yet, and local library catalogue searching should for a considerable time supplement engine searching. However, the trend is now clear, and libraries will not be able to stop it. Instead, they should focus on flowing with the trend intelligently and work practically to make their resources searchable and retrievable through search engines.

\section{The lean library}

The escalating costs of maintaining extensive, commercially based collections of electronic materials as well as a diminishing financial base will make it necessary for many libraries to make radical changes in their mode of operation. Self-service systems, maximum use of information technology, and rationalisation will be necessary. Also, libraries will have to focus on what should be their core functions in the future, and a number of traditional functions will be handed over to suppliers. The result will be a continuous reduction of staff resources used on internal processing and routine functions.

Library work will be a front-end job, in direct contact with users, with important consequences for the size and composition of staff. Academic library structures should be simple and effective and reflect the needs and structure of the university rather than parochial considerations of internal library functioning. Decision structures of the university libraries should be highly tuned to the needs and decision structures of the university.

\section{CONCLUSION}

Prophesying about the future is a difficult thing, and I do not pretend that the viewpoints, which I have presented today, are true - they are viewpoints! My main thesis is not that our library future will be this or that particular one. Rather, my main thesis is the following: important and to some extent irresistible forces are at work which will radically change academic library work in the future. If we ignore these drivers of development, we shall eventually disappear. If we understand them, we can intelligently choose the directions which will ensure our relevance and usefulness to academic research, teaching and study also in the next information age which will be the period of the internet, of the search engines and - eventually of the disappearance of print media as the major medium of scholarly information.

\section{WEB SITES REFERRED TO IN THE TEXT}

EBSLG - European Business Schools Librarians' Group. http://www.ebslg.org/public/default_public.htm

Copenhagen Business School. http://www.cbs.dk/

Google. http://www.google.com/

Google Scholar. http://www.scholar.google.com/ 